\section{- OPEN ACCESS}

\title{
Is the mechanism of re-expansion pulmonary oedema in a heart-lung interaction?
}

\author{
Candy Masego Mokotedi, Martin Balik
}

Department of Anaesthesia and Intensive Care, 1st Medical Faculty, Charles University, Prague, Czech Republic

\section{Correspondence to} Dr Martin Balik, martin.balik@ vfn.cz

Accepted 12 June 2017

\section{CrossMark}

To cite: Mokotedi CM, Balik M. BMJ Case Rep Published Online First: [please include Day Month Year]. doi:10.1136/bcr-2017 219340

\section{SUMMARY}

The mechanism of re-expansion pulmonary oedema (Re$\mathrm{PE}$ ) is unclear. There are multiple variables in play when evaluating the response to evacuation of pleural fluid. We present an educational case of a critically ill patient admitted for respiratory failure who was fully dependent on ventricular pacing set at a constant rate throughout the episode of Re-PE. The transthoracic echocardiography (TTE) showed an ejection fraction of $38 \%$, moderate mitral regurgitation (MR), mildly dilated right ventricle and moderate pulmonary hypertension. A pleural tap evacuated $850 \mathrm{~mL}$ of transudate, which was followed by tachypnoea and deteriorating oxygenation. Another repeat TTE revealed a Re-PE with elevated left ventricular end-diastolic pressure, severe MR, increased pulmonary hypertension and a decrease in stroke volume. There were no parallel changes in ventilation modality, heart rate, fluid therapy and vasopressor dosage. The treatment was initiated with dobutamine. The patient was extubated the next day and was later discharged to the cardiology department.

\section{BACKGROUND}

Re-expansion pulmonary oedema (Re-PE) reportedly has an incidence of $0.2 \%$ to $14 \%$ and, recently has been shown to be $<1 \%{ }^{12}$ The mechanism of Re-PE is unclear. A possible causative link is sought in amount of fluid removed, applied negative suction pressure and duration of lung collapse. The cut-off for amount drained is reported in a wide range between 1.0 and 6.5 litres. ${ }^{1}$ Mentioned also is an increased likelihood of Re-PE in patients with lung collapse lasting more than 7 days and particularly in those who need more than 3 litres of pleural fluid drained. ${ }^{2}$

There are multiple variables when evaluating the response to evacuation of pleural fluid which may include changes in blood pressure, heart rate, contractility, filling pressures and gas exchange.

We present an educational case of a chronic cardiac patient fully dependent on a single-chamber ventricular pacemaker (VVI) pacing set at a constant rate throughout the episode of Re-PE.

\section{CASE PRESENTATION}

A 75 -year-old man was admitted for 4 days of progressive dyspnoea to the pulmonary department. The patient's medical history consisted of chronic heart insufficiency with a dual chamber (DDD type) pacemaker implanted 8 years ago for intermittent symptomatic atrioventricular blockage, arterial hypertension, type 2 diabetes mellitus with complications of chronic renal insufficiency and polyneuropathy.

He was started on antibiotics due to clinical suspicion of pneumonia along with elevated inflammatory markers ( $\mathrm{C}$ reactive protein, leucocytes). Furosemide was also given with regards to high admission brain natriuretic peptide. Due to progression of respiratory insufficiency, the patient was transferred to the intensive care department (ICU).

\section{INVESTIGATIONS}

On admission, he was conscious, co-operative, tachypnoeic with peripheral saturation of $85 \%$ on $10 \mathrm{~L} / \mathrm{min} \mathrm{O}_{2}$ given via Hudson mask. Patient was normotensive $(130 / 70 \mathrm{~mm} \mathrm{Hg})$ with atrial fibrillation (AF) and fully dependent on VVI pacing to $70 \mathrm{bpm}$ (beats per minute). Cardiac biochemistry (troponin I, CK-MB mass, myoglobin) was negative. Transthoracic echocardiography (TTE) was performed which showed congestive heart failure, hypokinetic anteroseptal left ventricular (LV) wall and apex with an ejection fraction (EF) of 38\%, moderate mitral regurgitation (MR), dilated left atrium (LA), mild aortic regurgitation (AR), moderately dilated right ventricle (RV) with a tricuspid annular plane systolic excursion (TAPSE) of $23 \mathrm{~mm}$, moderate tricuspid regurgitation and an estimated right-sided pleural effusion of $300-400 \mathrm{~mL}$. $^{3}$ TAPSE correlates with RV longitudinal contractility and RVEF in the absence of tricuspid valve surgery, normal value is above $18 \mathrm{~mm} .{ }^{4}$

With a cardiac output (CO) of $3.5 \mathrm{~L} / \mathrm{min}$, on non-invasive ventilation (pressure support ventilation (PSV) 10 mbar, positive end expiratory pressure (PEEP) 6 mbar, fractional inspired oxygen $\left(\mathrm{FiO}_{2}\right)$ 0.60) and diuretics (furosemide by continuous infusion 3-5 mg/hour titrated according to his urine output), the patient had his VVI pacing reset to $90 \mathrm{bpm}$.

Despite therapy, 36 hours after admission, there were signs of limited aeration of the right lower lobe with bronchial breathing (figure 1A). The patient had to be intubated for exhaustion, and a bronchoscopy was performed which excluded atelectasis, confirmed tracheobronchitis and enabled a bronchoalveolar lavage from the right lower lobe to be obtained and be sent for microbiological analysis. A norepinephrine infusion (NAD) was then started at $0.15 \mu \mathrm{g} / \mathrm{kg} / \mathrm{min}$. Shortly after bronchoscopy, the patient was placed on PSV of $14 \mathrm{cmH}_{2} \mathrm{O}$, PEEP of $8 \mathrm{cmH}_{2} \mathrm{O}$ and $\mathrm{FiO}_{2} 0.50$. 


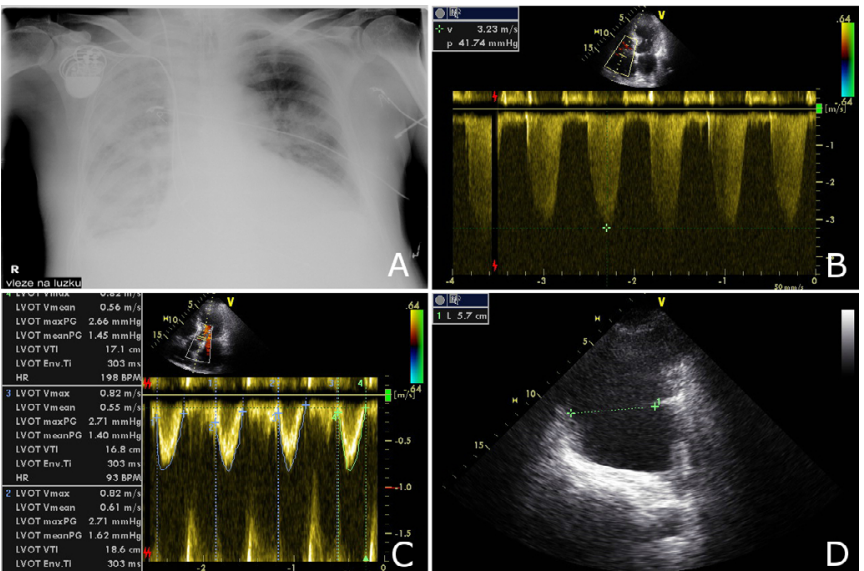

Figure 1 All parameters are taken with a heart rate (HR) of $90 \mathrm{bpm}$ (beats per minute). (A) Chest X-ray after intubation and central venous catheter insertion on pressure support ventilation and vasopressor infusion. (B) Pulmonary artery systolic pressure of $50 \mathrm{~mm} \mathrm{Hg}$ was equal to the transtricuspid continuous wave Doppler systolic gradient of $42 \mathrm{~mm} \mathrm{Hg}$ plus central venous pressure of $8 \mathrm{~mm} \mathrm{Hg}$. (C) Mean velocity time interval in the left ventricular outflow tract (LVOT) was $17.5 \mathrm{~cm}$. (D) Right pleural fluid separating parietal and visceral pleura in the thoracic transverse plane taken above the right diaphragm in the posterior axillary line. Volume estimate in millilitres is equal to the maximum separation in the transverse plane in millimetres multiplied by $20 .^{3}$

The patient was thus on a vasopressor and mechanical ventilation with persisting loss of aeration of the right lower lobe. Therefore, another TTE was done on VVI 90/min (see video 1) which showed moderate LV dysfunction and regional wall motion abnormalities of the anterior wall and apex. There was a moderate-to-severe MR into a dilated LA (biplanar LA volume indexed to body surface area $80 \mathrm{~mL} / \mathrm{m}^{2}$ ) which was in AF. The RV was severely dilated with moderately decreased contractility, the right atrium was dilated and the estimated pulmonary artery systolic pressure (PAPs) was $50 \mathrm{~mm} \mathrm{Hg}$ (figure 1B). Mild AR was found, stroke volume (SV) was $72 \mathrm{~mL}$ (figure $1 \mathrm{C}$ ) and $\mathrm{CO}$ was $6.4 \mathrm{~L} / \mathrm{min}$. Right pleural fluid estimate was $800-1000 \mathrm{~mL}$ (figure 1D).

A right pleural tap was performed with a $12 \mathrm{~F}$ drain and a closed collection system, and $850 \mathrm{~mL}$ of transudate was evacuated without an active suction (figure $2 \mathrm{~A}$ ).

With the patient being constantly on VVI 90/min and on the same PSV settings, he became tachypnoeic with increasing

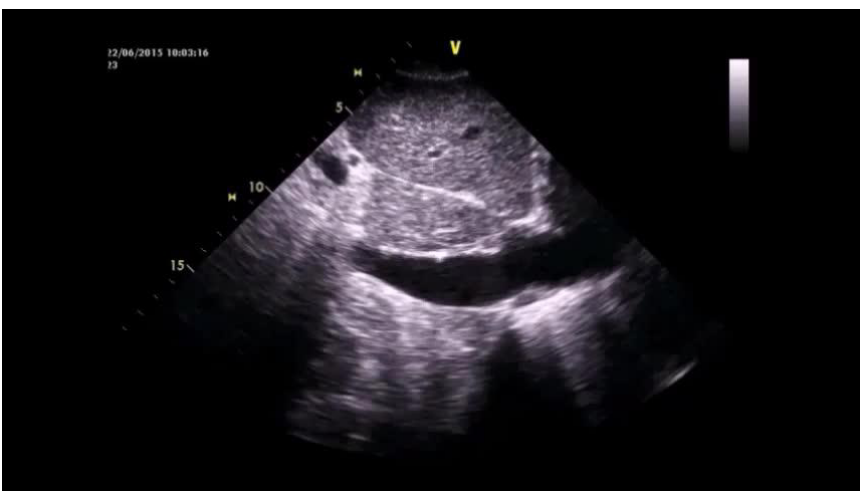

Video 1 Apical four-chamber view showing a hypokinetic apex and interventricular septum, dilated left atrium and right ventricle and collapsibility of the inferior vena cava in inspirium.

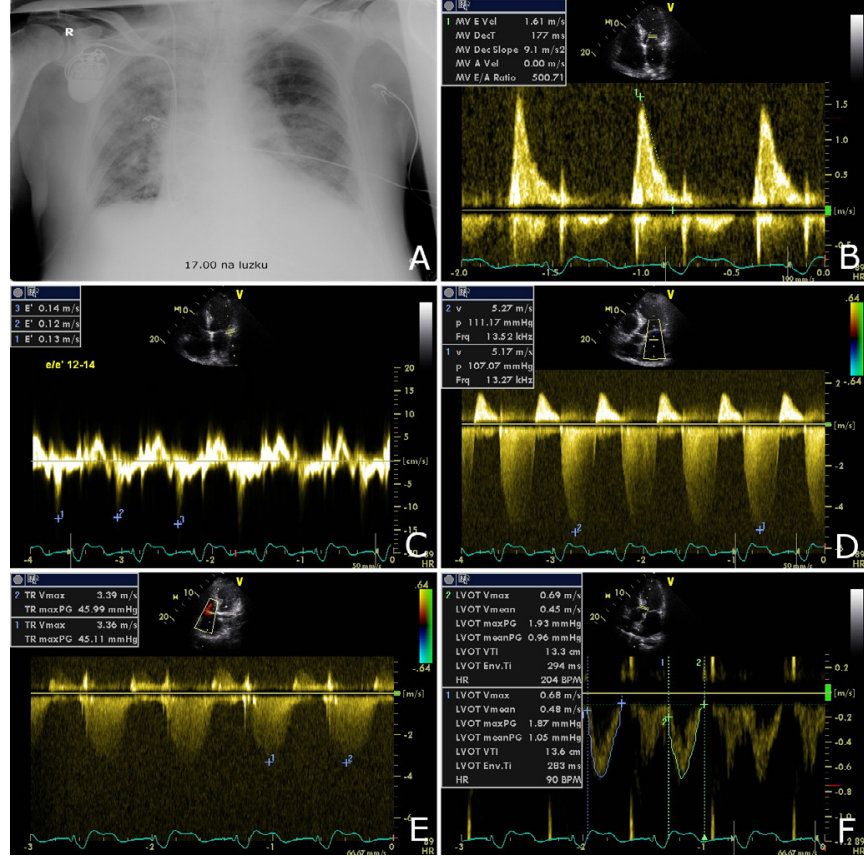

Figure 2 All parameters are taken with a heart rate (HR) of $90 \mathrm{bpm}$ (beats per minute). (A) Chest X-ray immediately after drainage of $850 \mathrm{~mL}$ from the right pleura. (B) Transmitral pulsed wave Doppler in a patient with atrial fibrillation and a significant mitral regurgitation (MR) (E $1.61 \mathrm{~m} / \mathrm{s})$. (C) Lateral velocity time interval (VTI) with measured $\mathrm{e}^{\prime}$ of 12-13 cm/s. E/e' was 12-14 indicating an elevated left ventricular end-diastolic pressure. (D) Systolic continuous wave (CW) Doppler of an MR jet showing peak systolic gradient of $109 \mathrm{~mm} \mathrm{Hg}$. With a systolic blood pressure (BPs) of $136 \mathrm{~mm} \mathrm{Hg}$, the patient had a left atrial pressure of $27 \mathrm{~mm} \mathrm{Hg}$ (BPs-CWmax). (E) Systolic transtricuspid CW Doppler gradient of $45 \mathrm{~mm} \mathrm{Hg}$ added to a central venous pressure of $12 \mathrm{~mm} \mathrm{Hg}$ produced an estimate of $57 \mathrm{~mm} \mathrm{Hg}$ pulmonary artery systolic pressure. TR, tricuspid regurgitation. (F) After drainage, the mean VTI in the left ventricular outflow tract (LVOT) was $13.4 \mathrm{~cm}$.

requirements for oxygen $\left(\mathrm{FiO}_{2} 0.80\right)$, exhibited no signs of a pneumothorax (video 2) and had decreased blood pressure and urine output. The control TTE revealed an elevated left ventricular end-diastolic pressure (LVEDP) (lateral mitral E/e' 12-13, figure $2 \mathrm{~B}, \mathrm{C}$ ), a moderate-to-severe $\mathrm{MR}$ into a dilated LA with a continuous wave $(\mathrm{CW})$ Doppler-based left atrial pressure

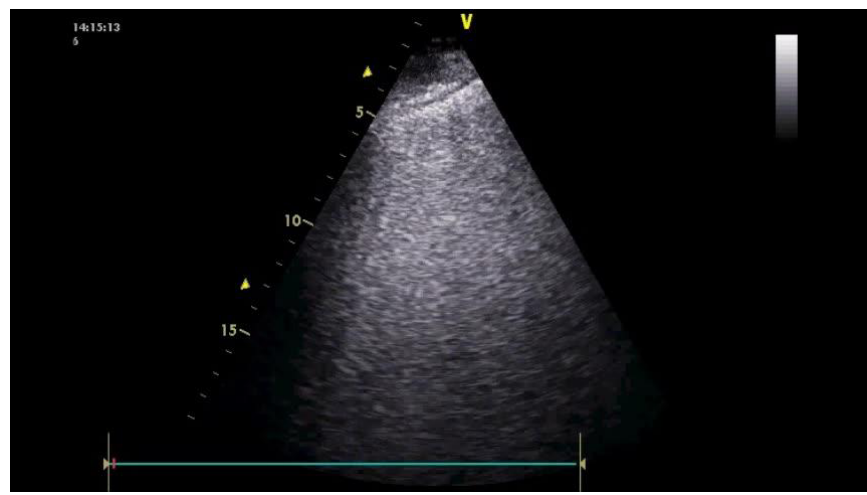

Video 2 The right lung after drainage of the pleural effusion showing pleural sliding, lung pulse and multiple coalescent $B$ lines. The findings are consistent with alveolar-interstitial syndrome (lung oedema) and excludes a pneumothorax. 


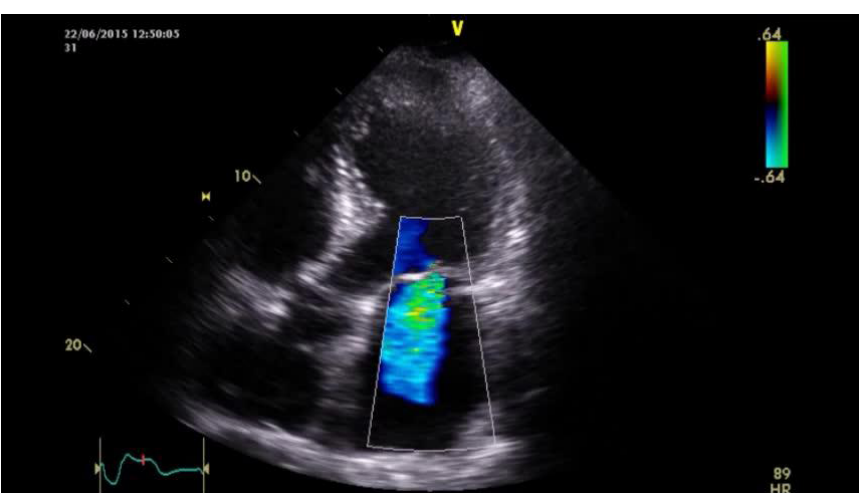

Video 3 Apical five-chamber view with moderate-to-severe mitral regurgitation into a dilated left atrium, dilated right ventricle and noncollapsing inferior vena cava during the respiratory cycle.

(LAP) estimate of $27 \mathrm{~mm} \mathrm{Hg}$ (figure 2D), an increase of PAPs to $57 \mathrm{~mm} \mathrm{Hg}$ (figure 2E), a non-collapsing inferior vena cava with spontaneously triggered inspirium (video 3 ) and a decreased SV of $56 \mathrm{~mL}$ (figure $2 \mathrm{~F}$ ) with a CO of $5.04 \mathrm{~L} / \mathrm{min}$.

The worsening lung congestion in parallel with systolic heart dysfunction after drainage of a large pleural effusion in a patient with no changes in ventilation modality, heart rate, fluid therapy and vasopressor dosage was concluded as a Re-PE.

\section{DIFFERENTIAL DIAGNOSIS}

1. Congestive heart failure-echocardiography confirmed the diagnosis, enabled to estimate elevated heart filling pressures with further impact on therapy. The ultrasound examination also helped diagnose and quantify a large fluidothorax with an implication for a safe drainage.

2. Acute myocardial infarction-excluded by repeatedly negative cardiac biochemistry (troponin I and CK-MB mass) taken in a patient with a non-diagnostic 12-lead ECG due to VVI pacing and not changing regional wall motion abnormalities seen on echocardiography.

3. Pulmonary embolism-the patient showed a dilated RV with preserved contractility throughout this episode, without any signs of acute cor pulmonale or changes in the elimination of $\mathrm{CO}_{2}$. After the drainage of pleural fluid which was performed on systemic anticoagulation, the mild increase of pulmonary artery pressure could be ascribed to the parallel increase of LAP, that is, presence of postcapillary pulmonary hypertension in heart failure. This deterioration after drainage was reversed swiftly with improvement of the LV function on dobutamine. All of this renders a possible diagnosis of a significant pulmonary embolism very unlikely as a cause of his transient deterioration.

4. Respiratory insufficiency due to tracheobronchitis or pneumonia-diagnosed with the help of positive inflammatory markers and clinical signs of increased bronchial secretions. Fibreoptic bronchoscopy confirmed the diagnosis of tracheobronchitis and excluded atelectasis.

5. Pneumothorax-excluded predrainage and postdrainage by the presence of pleural sliding, B lines and a lung pulse. A large pneumothorax was also excluded by the chest X-ray taken after admission to the ICU and again after pleural drainage.

\section{TREATMENT}

The patient was administered dobutamine $5.0 \mu \mathrm{g} / \mathrm{kg} / \mathrm{min}$ with a positive effect on CO (figure 3) and oxygenation. The

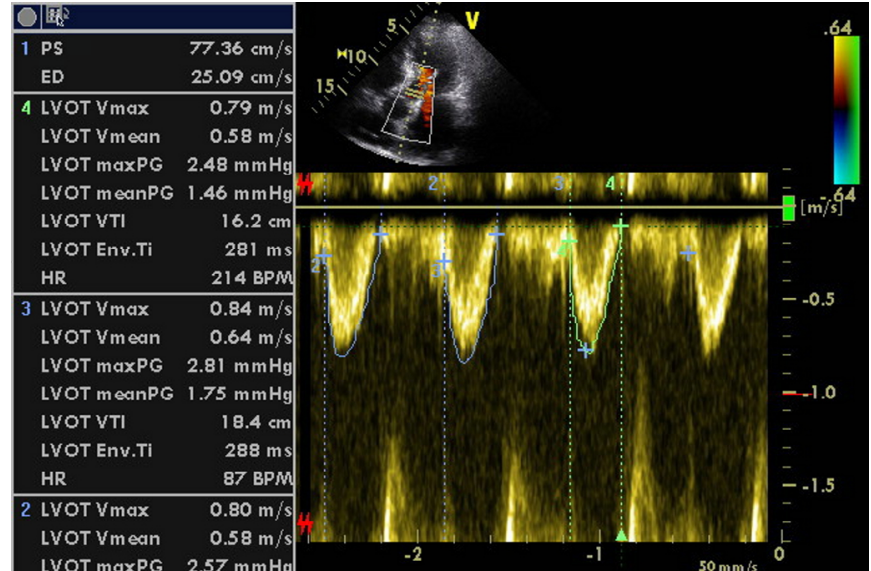

Figure 3 A control transthoracic echocardiography on dobutamine 5 $\mu \mathrm{g} / \mathrm{kg} / \mathrm{min}$ showing increased mean velocity time interval (VTI) in the left ventricular outflow tract (LVOT) to $17.3 \mathrm{~cm}$. Heart rate (HR) is 90 bpm (beats per minute). ED end-diastolic; PS peak systolic

decision for inotropic support as first-line therapy rather than increasing the intermittent positive pressure ventilation (IPPV) requirements was supported by the presence of congestive heart failure with pulmonary hypertension and RV dysfunction. With a positive response to therapy, he was weaned off the mechanical ventilation within 24 hours, extubated and continued on Hudson mask and $\mathrm{FiO}_{2}$ of 0.6.

\section{OUTCOME AND FOLLOW-UP}

The patient was then discharged to a high dependency unit after another 24 hours with sufficient expectoration, without dobutamine, on antibiotics, NAD $0.08 \mu \mathrm{g} / \mathrm{kg} / \mathrm{min}$ and VVI $90 \mathrm{bpm}$. He was discharged on day 19.

\section{DISCUSSION}

This case shows an episode of Re-PE in a patient after drainage of a large pleural effusion, with a constant heart rate and IPPV settings. His previously stable haemodynamics decompensated after drainage of $850 \mathrm{~mL}$ without any application of negative suction pressure. The observation of a Re-PE suggests that it might be rather a cardiac decompensation in a large pleural effusion which had increased the pleural pressure and decreased the LV transmural pressure. During drainage, the LV afterload increased with a parallel decrease of LV systolic performance. All this happened in a septic patient with chronic ischaemic heart disease and moderately decreased LV systolic function regardless of being treated on IPPV. The mechanism of so-called Re-PE could be due to heart-lung interactions during and after drainage rather than in re-expansion of the lung compressed by an effusion. Administration of inotropic therapy improved the Re-PE symptoms.

The haemodynamic observations were facilitated by the routinely performed bedside critical care echocardiography. Keys to understanding the case were the observations of worsening postcapillary pulmonary hypertension and SV decrease after drainage of a significant fluidothorax. The regular Doppler indices of LV filling pressures are fraught with limitations in non-sinus rhythm; however, the transmitral and tissue Doppler parameters demonstrate improved specificity in atrial arrhythmia with a regular ventricular response and with a peripheral pulse deficit (ppd) of up to 10-15 bpm. The high transmitral E of 1.61 $\mathrm{m} / \mathrm{s}$ may not be useful for confirmation of an elevated LVEDP 
as a sole parameter due to concomitant significant MR. Deceleration time of early diastolic transmitral flow of $177 \mathrm{~ms}$ (figure 2B) was borderline and did not exclude elevated filling pressures with its specificity of about $80 \%-85 \% .{ }^{5}$ In this case, the heart was constantly paced at $90 /$ min with no ppd and a lateral E/ $\mathrm{e}^{\prime}$ above 12 suggested elevated LVEDP. This was confirmed by the LAP estimate using the $\mathrm{CW}$ signal of the $\mathrm{MR} .^{5}$

On Re-PE incidence, Echevarria et $a l^{2}$ provided an insightful paper where they went through Medline and searched for papers dated from 1950 to January 2008. Of the 233 papers, 13 provided some insight into the existence of Re-PE with a reported incidence of $0 \%-1 \%$. Mynarek $e t \mathrm{al}^{7}$ found zero occurrence of Re-PE after investigating 711 ultrasound-guided thoracentesis procedures performed on 371 patients. Rozenman $e t$ al $^{8}$ detailed their experience over an 8-year period where 180 patients who experienced 320 episodes of pneumothorax, and only 3 of 320 cases of Re-PE were diagnosed. All these insightful papers conclude that Re-PE is overall a rare entity.

Stawicki $e t a l^{9}$ stated some risk factors of Re-PE as: size of effusion or pneumothorax, duration of collapse, technique used for re-expansion and pulmonary artery pressure changes among others. The British Thoracic Society guidelines advocate for pleural drainage of no more than 1.5 litres. ${ }^{1}$ Sohara ${ }^{10}$ has alluded to these being the two major causes of Re-PE: (1) histological pulmonary microvasculature abnormality due to continual lung collapse and (ii) mechanical stress imposed on pulmonary microvasculature by the re-expansion process.

Moving on to evaluate the relationship between cardiac compromise and Re-PE, Chowdhary et $a l^{11}$ documented a fatal Re-PE in a patient with LV compromise. They postulated that lung re-expansion causes shifts in fluid, and as a result, the oedematous lung impedes ventricular filling in a situation where the LV is compromised. The authors thus suggest that thoracentesis in LV compromise be prudently performed. There is no mention of incorporation of echocardiography to monitor the heart function or preload assessment in light of knowledge of a compromised ventricle when performing a thoracentesis. Thus, a question sneaks into the reported relationship between a 'non-compliant LV' and Re-PE which may be reversed with the primary cause known in LV compromise.

Tan $e t a l^{12}$ studied the haemodynamic traits among patients with pneumothorax and documented an increase in $\mathrm{CO}$ after chest tube insertion and alluded to this as a possible indicator to a possible occurrence of Re-PE. Their data, however, do not confer any significant difference. The authors also reported no change in the pulmonary capillary wedge pressure in the patients who developed Re-PE, which is still possible after drainage in obstruction. They thus concluded that the reason for the increase in CO seen here is a topic for further research.

To comprehend heart-lung interactions, the effects of modifications in intrathoracic pressure (ITP) and in the volume of the lung on the venous return and on LV ejection are vital. ${ }^{13}$ Increases in pleural pressure (due to a pleural effusion in this instance) decrease the transmural pressure of the LV, therefore, decreasing LV ejection pressure which will in turn lead to decreased pressures upstream. With thoracocentesis, the pleural pressure decreases, and at constant arterial pressure, the LV ejection pressure increases. ${ }^{14}$ Also, very negative swings in ITP (eg, negative suction pressure) increase LV afterload which may lead to LV failure and pulmonary oedema particularly if LV systolic function is already compromised.

An important variable to be considered is the difference between spontaneously triggered ventilation modality (in our case PSV) and mandatory mode of mechanical ventilation. In our case, the course of ITPs likely resembled spontaneous ventilation. In a fully mechanically ventilated patient without spontaneous breathing activity, ventilator-generated pressures in inspirium might be theoretically higher, and the impact of pleural fluid removal on the LV transmural pressure might be tapered because of higher mean airway and plateau pressures.

In conclusion, Re-PE seems to be a rare finding and might be anticipated in a compromised LV operating at elevated filling pressures, and attention should be paid particularly to large pleural effusions. Regardless of mechanical ventilation, if an elevated LVEDP is found on echocardiography or on invasive monitoring, a decrease of SV and CO might be observed with pleural drainage. This mechanism deserves further attention in the form of a prospective study applying bedside echocardiography in the critically ill with various aetiologies of pleural effusions and modalities of IPPV.

\section{Learning points}

- Re-expansion pulmonary oedema (Re-PE) might be rather a cardiac decompensation in large pleural effusions increasing pleural pressure and decreasing left ventricle (LV) transmural pressure.

- During drainage, the pleural and intrathoracic pressures decrease and LV afterload increases with a parallel decrease of the LV systolic performance. This happened in a patient with moderately decreased LV systolic function regardless of being treated with intermittent positive pressure ventilation (IPPV).

- Re-PE could be due to heart-lung interactions during and after pleural drainage.

- Re-PE seems to be a very rare finding and might be anticipated in a large pleural effusion drained in a patient with compromised LV operating at elevated filling pressures.

- This mechanism deserves further attention in the form of prospective studies applying bedside echocardiography in patients with various aetiologies of pleural effusions and on different modalities of IPPV.

Contributors CMM is a postgraduate student in the field of Imaging methods at the 1st Medical Faculty of the Charles University in Prague. MB, CMM's tutor and Head of the Intensive Care Unit of the Department of Anaesthesia and Intensive Care, General University Hospital in Prague, performed the echocardiographic examination and reviewed the original data. They both contributed to the write up of the manuscript.

Funding The study was supported inpart from projectreg.no. CZ.2.16/3.1.00/21565 from OP Prague Competitiveness.

Competing interests None declared.

Patient consent Obtained.

Provenance and peer review Not commissioned; externally peer reviewed.

Open Access This is an Open Access article distributed in accordance with the Creative Commons Attribution Non Commercial (CC BY-NC 4.0) license, which permits others to distribute, remix, adapt, build upon this work non-commercially, and license their derivative works on different terms, provided the original work is properly cited and the use is non-commercial. See: http://creativecommons.org/ licenses/by-nc/4.0/

(c) BMJ Publishing Group Ltd (unless otherwise stated in the text of the article) 2017. All rights reserved. No commercial use is permitted unless otherwise expressly granted.

\section{REFERENCES}

1 Havelock T, Teoh R, Laws D, et al. Pleural procedures and thoracic ultrasound: British Thoracic Society pleural disease guideline 2010. Thorax 2010;65:i61-i76.

2 Echevarria C, Twomey D, Dunning J, et al. Does re-expansion pulmonary oedema exist? Interact Cardiovasc Thorac Surg 2008;7:485-9. 
3 Balik M, Plasil P, Waldauf P, et al. Ultrasound guided thoracentesis in mechanically ventilated patients. Intensive Care Med 2006;32:318-21.

4 Rudski LG, Lai WW, Afilalo J, et al. Guidelines for the echocardiographic assessment of the right heart in adults: a report from the American Society of Echocardiography endorsed by the European Association of Echocardiography, a registered branch of the European Society of Cardiology, and the Canadian Society of Echocardiography. Am Soc Echocardiogr 2010;23:685-713.

5 Watanabe T, Iwai-Takano M, Oikawa M, et al. Optimal noninvasive assessment of diastolic heart failure in patients with atrial fibrillation: comparison of tissue Doppler echocardiography, left atrium size, and brain natriuretic peptide. J Am Soc Echocardiogr 2008;21:689-96.

6 Nagueh SF, Appleton CP, Gillebert TC, et al. Recommendations for the evaluation of left ventricular diastolic function by echocardiography. Eur J Echocardiogr 2009;10:165-93.

7 Mynarek G, Brabrand K, Jakobsen JA, et al. Complications following ultrasoundguided thoracocentesis. Acta Radiol 2004;45:519-22.
8 Rozenman J, Yellin A, Simansky DA, et al. Re-expansion pulmonary oedema following spontaneous pneumothorax. Respir Med 1996;90:235-8.

9 Stawicki S, Sarani B, Braslow B. Reexpansion pulmonary edema. International Journal of Academic Medicine 2017;3:59.

10 Sohara Y. Reexpansion pulmonary edema. Ann Thorac Cardiovasc Surg 2008;14:205-9.

11 Chowdhary M, Peng EW, Sarkar PK. The risk of fatal re-expansion pulmonary oedema in poor left ventricular reserve. Interact Cardiovasc Thorac Surg 2009:9:350-1.

12 Tan HC, Mak KH, Johan A, et al. Cardiac output increases prior to development of pulmonary edema after re-expansion of spontaneous pneumothorax. Respir Med 2002:96:461-5.

13 Pinsky MR. Heart-lung interactions. Curr Opin Crit Care 2007;13:528-31.

14 Cheifetz IM. Cardiorespiratory interactions: the relationship between mechanical ventilation and hemodynamics. Respir Care 2014;59:1937-45.

Copyright 2017 BMJ Publishing Group. All rights reserved. For permission to reuse any of this content visit http://group.bmj.com/group/rights-licensing/permissions.

BMJ Case Report Fellows may re-use this article for personal use and teaching without any further permission.

Become a Fellow of BMJ Case Reports today and you can:

- Submit as many cases as you like

- Enjoy fast sympathetic peer review and rapid publication of accepted articles

- Access all the published articles

- Re-use any of the published material for personal use and teaching without further permission

For information on Institutional Fellowships contact consortiasales@bmjgroup.com

Visit casereports.bmj.com for more articles like this and to become a Fellow 